\title{
Morphological Investigation of Foamed Aluminum Parts Produced by Melt Gas Injection
}

\author{
R. Surace, ${ }^{1}$ L. A. C. De Filippis, ${ }^{2}$ E. Niini, ${ }^{3}$ A. D. Ludovico, ${ }^{1}$ and J. Orkas ${ }^{3}$ \\ ${ }^{1}$ Dipartimento di Ingegneria Meccanica e Gestionale, Politecnico di Bari, viale Japigia 182, 70126 Bari, Italy \\ ${ }^{2}$ Dipartimento di Ingegneria dell'Ambiente e per lo Sviluppo Sostenibile, Politecnico di Bari, viale del Turismo 8, \\ 74100 Taranto, Italy \\ ${ }^{3}$ Faculty of Engineering and Architecture, Helsinki University of Technology, Otakaari 4, 02015 Espoo, Finland \\ Correspondence should be addressed to R. Surace, r.surace@poliba.it
}

Received 26 May 2008; Revised 22 December 2008; Accepted 3 February 2009

Recommended by Jack Gillespie

\begin{abstract}
Porous metal materials are a new class of materials with low densities, large specific surface, and novel physical and mechanical properties. Their applications are extremely varied: for light weight structural components, for filters and electrodes, and for shock or sound absorbing products. Recently, interesting foaming technology developments have proposed metallic foams as a valid commercial chance; foam manufacturing techniques include solid, liquid, or vapor state methods. The foams presented in this study are produced by Melt Gas Injection (MGI) process starting from melt aluminum. The aim of this investigation is to obtain complex foamed aluminum parts in order to make the MGI more flexible. This new method, called MGI-mould process, makes possible to produce 3D-shaped parts with complicated shape or configuration using some moulds obtained by traditional investment casting process.
\end{abstract}

Copyright (C) 2009 R. Surace et al. This is an open access article distributed under the Creative Commons Attribution License, which permits unrestricted use, distribution, and reproduction in any medium, provided the original work is properly cited.

\section{Introduction}

The Cymat/Alcan and Norsk Hydro melt-foaming process, called Melt Gas Injection (MGI), is a continuous, gas injection method developed simultaneously and independently by Alcan [1] and Norsk Hydro [2] in the late 1990s. The starting material, usually a metal matrix composite, is molten with conventional foundry equipment and transferred to a tundish where gas is injected via a nozzle incorporated into a rotating impeller, thus forming a dispersion of small bubbles. The reinforcing particles are typically $\mathrm{SiC}$ or $\mathrm{Al}_{2} \mathrm{O}_{3}$, and their volume fraction ranges from $10 \%$ to $20 \%$ and the mean size from 5 to $20 \mu \mathrm{m}$. The ceramic particles trap gas bubbles owing to the favorable interface energy and serve as stabilizer of the cell walls and delay their coalescence. They also reduce the velocity of the rising bubbles by increasing the viscosity of the melt [3-5]. The bubbles size can be controlled by adjusting the gas flow rate, the propeller design (number of nozzles and their size), and its spin speed. Usually, the resulting foam is carried away by means of conveyor belt where it solidifies and cools. Figure 1(a) shows a sketch of the process [2].
The foam, obtained by MGI, usually presents a gradient in density and pores elongation as a natural consequence of the gravitationally induced drainage and the shearing forces of the conveyor belt that lead to distorted cells in the final product. This obviously has a pronounced effect on the mechanical properties which become anisotropic [6]. The situation could be improved by pulling off the foam vertically [7]. Moreover, obtaining shaped parts by this process is very difficult for the ceramic particles that make difficult the cutting. Attempts for making shaped parts have been undertaken by casting the semiliquid foam into moulds or by shaping the emerging foam with rolls, thus trying to eliminate this disadvantage. The first reference technique for producing shaped parts is from Kenny and Thomas [8]; Figure 1(b) shows a sectional view of the metal foam generating box and the mould for forming shaped parts. The freshly formed stabilized liquid foam is drawn above a preheated mould mounted on a support. A platen moved downwardly, pushing the foam into the mould to form a shaped product with a densified flange area. Kleinheyer and Bilz [9] proposed the use of a mould on the top of aluminum melt to collect foam and of a suction device. Nichol [10] 


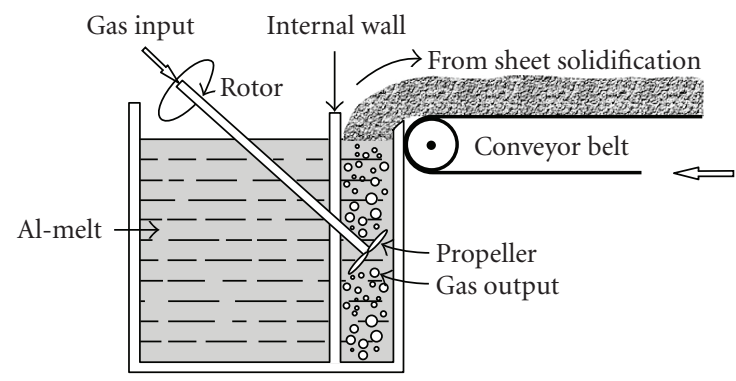

(a)

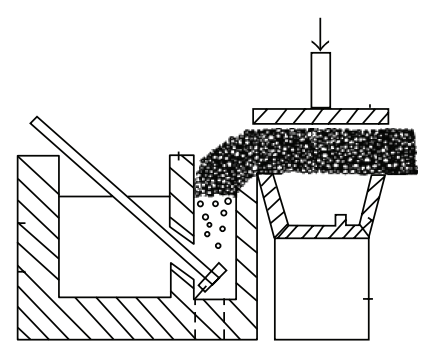

(b)

Figure 1: Apparatus for MGI [2-6].

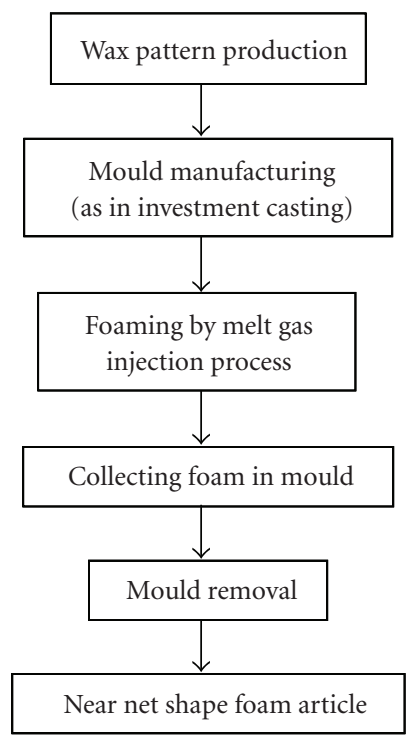

FIgURE 2: Work flow of MGI-mould process.

patented a metal foam casting apparatus to obtain formed articles with a ladle, within the heated chamber, for drawing a foam sample and for transporting to a mould.

The aim of this investigation is to obtain complex foamed aluminum parts in order to make the MGI more flexible. This new method, called MGI-mould process, makes possible to produce $3 \mathrm{D}$-shaped parts with complicated shape or configuration. These parts are expected to be utilized as filling material and for encasing in components without machining. In the designed equipment, the generated bubbles float to the surface as in the traditional MGI where they are guided directly into a ceramic mould put above the furnace crucible. The foaming propeller is inserted through the mould in a suitable place. The moulds are prepared by traditional investment casting process, also known as the lost wax process [11], and different shapes are realized functionally to study foaming in complex parts. After foaming, the ceramic shell material is mechanically removed from foam and sometimes by high-pressure water blasting. Figure 2 shows the work flow of MGI-mould process where, differently from literature previously cited, the mould is

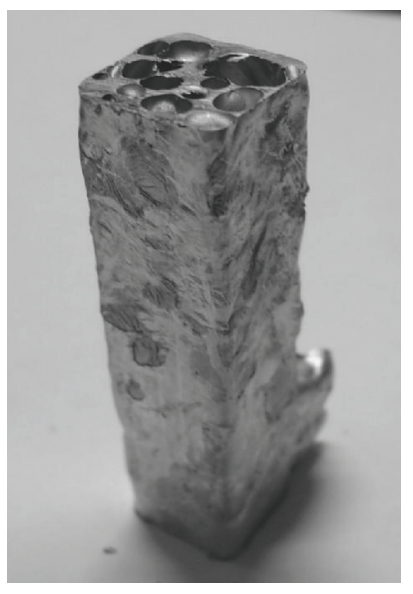

FIgURE 3: Shaped foam part with dense skin $(19 \times 19 \times 80 \mathrm{~mm})$.

placed directly on the crucible with a fair simplification of equipments.

Foam parts (straight rectangular and cylindrical bars) show a closed surface skin with a thickness comparable to the cell-wall thickness (Figure 3), and this is a prerequisite for encasing especially by casting. Korner et al. [12] reported that two production routes result in a solid surface skin: the powder compact foaming, like Alulight, and the Formgrip process. Both processes comprise baking of a foamable precursor material in a mould. They differ in the way the precursor material is produced. Instead, in this investigation, aluminum foam-shaped parts with dense skin are realized by MGI-mould process, and they could be very suitable for encasing and for filling components.

\section{Experimental Setup}

Several parameters influence the quality of the final foam product:

(i) matrix alloy composition, particles (composition, shape, size, volume fraction);

(ii) particle-surface interactions;

(iii) gas (composition and purity, flow rate, pressure);

(iv) foaming temperature; 


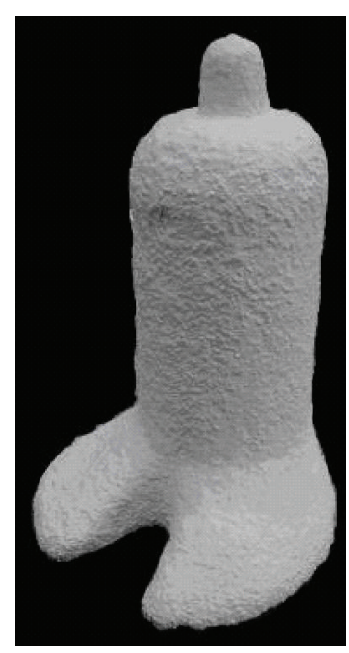

(a)

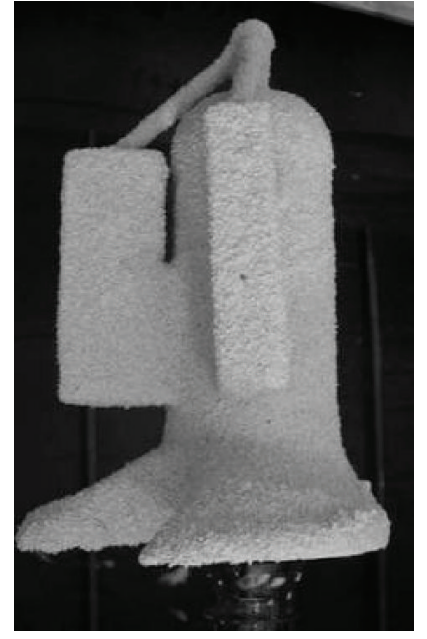

(b)

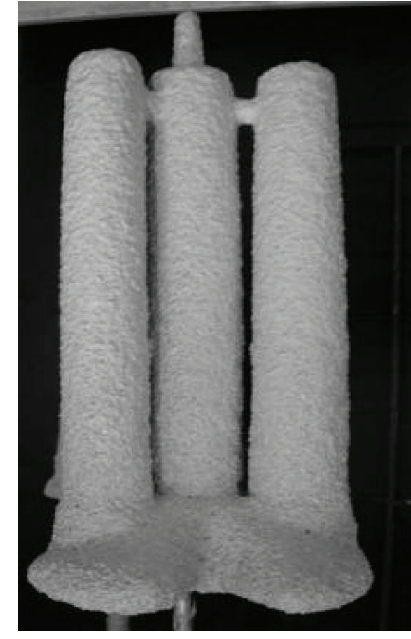

(c)

Figure 4: SM (a), ME (b) and BM (c).

(v) thermal processing conditions (holding time, cooling medium);

(vi) crucible (size and shape);

(vii) propeller (size and shape, direction of rotation, size of the panel, spin speed);

(viii) inclination of the system during foaming;

(ix) nozzle design.

Some of them were set following previous results of authors reported elsewhere [13] where a description of equipment was also given.

Duralcan metal matrix composite (A356/SiC/20p), with a particle size of approximately $12 \mu \mathrm{m}$, was used; flow rate was fixed at $4 \mathrm{~L} / \mathrm{min}$ and temperature in the range 670 $700^{\circ} \mathrm{C}$. In order to measure the relative stability of the Al foam in the liquid state, two different foaming gases (nitrogen and air) were performed. During experimental tests, a suction device has also been used. By the creation of a region of low pressure ( $0.8 \mathrm{bar})$, the gradient between this region and the ambient will propel matter toward the low-pressure area filling the moulds as desired. Thus, parts were manufactured at ambient pressure or in suction condition (suitable especially for high parts). As explained, the main difference with previous authors experimentation and literature reports is the use of ceramic moulds to collect the foam and to obtain shaped parts. The starting point of mould manufacturing is the production of a wax pattern, engineered as an inverted "mushroom" with a variable upper part to shape foam and with a large lower part to cover the crucible opening. The ceramic coating is built up through successive stages of dipping and stuccoing to build up a shell of a thickness sufficient to provide the strength required to process the mould successfully. The primary dip is usually different to the secondary or backing dip, and the grade of the used stucco particles may be coarser as the shell thickness increases. After drying, dewaxing, and sintering, the moulds were prepared for foaming by opening the upper part to
TABLE 1: Mould geometrical dimensions.

\begin{tabular}{lccc}
\hline Mould type & Shape & Dimension $[\mathrm{mm}]$ & Height $[\mathrm{mm}]$ \\
\hline SM & Cylindrical & $\varnothing 64$ & 100 \\
\multirow{2}{*}{ ME } & Parallelepiped & $19 \times 19$ & 80 \\
& & $32 \times 32$ & 80 \\
& & $\varnothing 24$ & 220 \\
BM & Cylindrical & $\varnothing 28$ & 220 \\
& & $\varnothing 33$ & 220 \\
\hline
\end{tabular}

ambient pressure and in other cases by fixing the connection for the suction device.

Following this procedure, three different geometries were realized: Simple Mould (SM), Mould with Extensions (ME), and Bars Mould (BM) showed in Figure 4. Table 1 reports the mould geometrical dimensions.

\section{Morphological Characterization}

In this section some fundamental investigations are described to clarify the foamed products quality and to optimize the process parameters. The obtained samples were cut with metallographic saw to minimize cell damage because, owing to the high content of ceramic particles, machining of MMC foams is sometimes a problem. The morphological parameters were measured in a $2 \mathrm{D}$ cross section by an image software tool, and cell walls were observed by a Scanning Electron Microscope Philips XL 20. The measured parameters are

(i) mould filling ability;

(ii) relative density;

(iii) relative density gradient;

(iv) cells area;

(v) cells shape. 
TABLE 2: Mould filling ability.

\begin{tabular}{lccccc}
\hline $\begin{array}{l}\text { Mould } \\
\text { type }\end{array}$ & Pressure & Gas & $\begin{array}{c}\text { Dimension } \\
(\mathrm{mm})\end{array}$ & $\begin{array}{c}\text { Sample } \\
\text { height } \\
(\mathrm{mm})\end{array}$ & Filling \\
\hline SM & Ambient & Nitrogen & $\varnothing 64$ & 73.01 & $73.0 \%$ \\
SM & Ambient & Air & $\varnothing 64$ & 86.76 & $86.8 \%$ \\
SM & Suction & Nitrogen & $\varnothing 64$ & 62.95 & $62.9 \%$ \\
ME & Ambient & Nitrogen & L 19 & 66.50 & $83.1 \%$ \\
& Ambient & Air & L 32 & 61.31 & $76.6 \%$ \\
ME & Suction & Nitrogen & L 19 & 72.65 & $90.8 \%$ \\
ME & & & L 32 & 72.79 & $91.0 \%$ \\
& & & $\varnothing 24$ & 161.0 & $73.2 \%$ \\
BM & Suction & \multirow{2}{*}{ Nitrogen } & $\varnothing 28$ & 122.8 & $55.8 \%$ \\
& & & $\varnothing 32$ & 199.5 & $90.7 \%$ \\
& & & $\varnothing 24$ & 111.0 & $50.4 \%$ \\
BM & Suction & \multirow{2}{*}{ Air } & $\varnothing 28$ & 77.55 & $35.2 \%$ \\
& & & $\varnothing 32$ & 212.0 & $96.4 \%$ \\
\hline
\end{tabular}

TABle 3: Process parameters and relative density.

\begin{tabular}{lccc}
\hline Mould type & Pressure & Gas & Relative density \\
\hline SM & Ambient & Nitrogen & 0.141 \\
SM & Ambient & Air & 0.179 \\
SM & Suction & Nitrogen & 0.142 \\
ME & Ambient & Nitrogen & 0.224 \\
ME & Ambient & Air & 0.227 \\
ME & Suction & Nitrogen & 0.229 \\
BM & Suction & Nitrogen & 0.249 \\
BM & Suction & Air & 0.218 \\
\hline
\end{tabular}

3.1. Mould Filling Ability. The mould filling ability was calculated by the ratio of final foam product height and the initial height of the moulds (Table 1) obtaining the following results (showed in Table 2).

(i) Simple moulds (SM) are relatively simple to fill with suction but at ambient pressure. The best result is an $86 \%$ filling, and it is due to the large diameter that favors the foam rising.

(ii) On the contrary, the filling of bars mould (BM) at ambient pressure is not possible for the narrow diameter of the bars, and no results have been obtained. Differently in suction condition, good results are possible (best filling 96.4\%).

(iii) The foam shows good filling ability in mould with extensions (ME) having a parallelepiped shape. As expected in suction condition, the filling is better (about 90\%) than at ambient pressure (about 70\%).

(iv) The type of injected gas do not show a clear influence on filling ability.

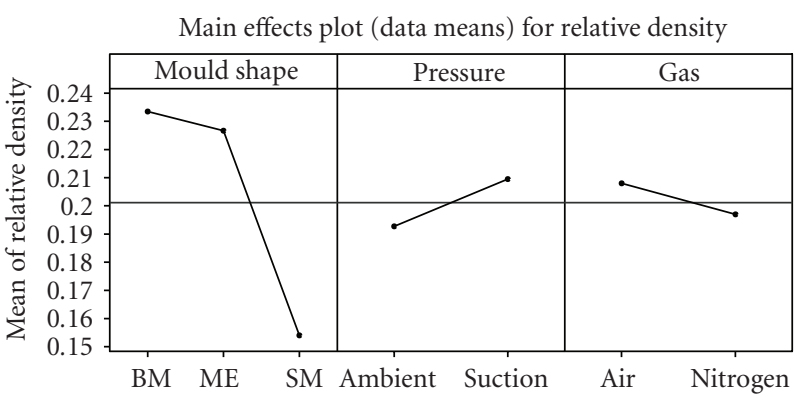

FIGURE 5: Main effect plot for relative density.

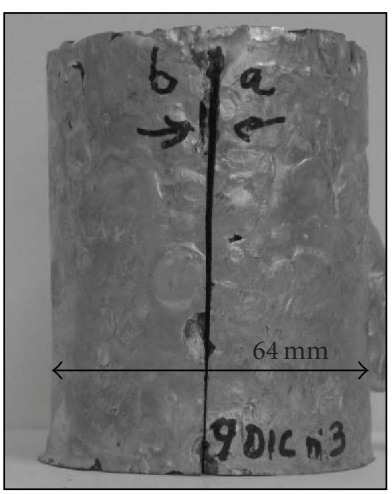

(a)

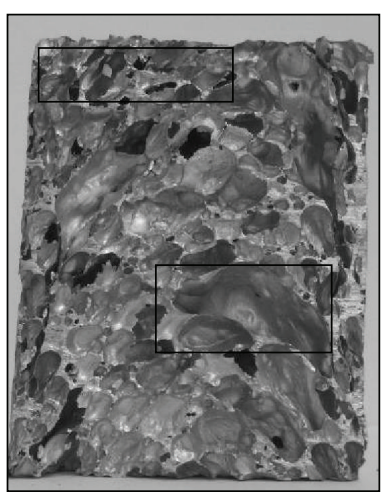

(b)
Figure 6: Cross section of an irregular cellular structure (SM, air, ambient).

3.2. Relative Density. The density of the cellular metal depends on the volume fraction of metal and gas. Consequently, cellular metals are characterized by the density compared to parent metal: the relative density. The used density of parent material (AlSi7 $+20 \mathrm{SiC}$ ) is $2.779 \mathrm{~g} / \mathrm{cm}^{3}$. The density for each specimen was determined from the sample weights and physical dimensions.

The average relative density is 0.201 with standard deviation of 0.0367 (Table 3 ). The values are comprised in the ranges reported from literature. Referring to the data, the factors influence is plotted using a statistical software (Minitab) evidencing the effects on relative density. The Main Effect Plot (Figure 5) can help the researcher to determine which factors affect the process from the line inclination of results with respect to the mean line; a higher deviation from the mean horizontal line represents a higher influence of the factor on the process results.

It is possible to consider that

(i) the type of injected gas is not crucial for relative density;

(ii) the pressure used during the test is not an influential factor on the relative density;

(iii) the mould shape reveals the most influencing factor. In fact the relative density is affected by the flow of the material in the shape; for large circular shape there is low resistance and high foam flow rate (low relative density for large circular shapes). 


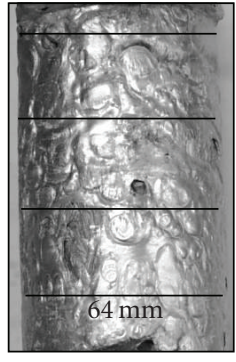

(a)

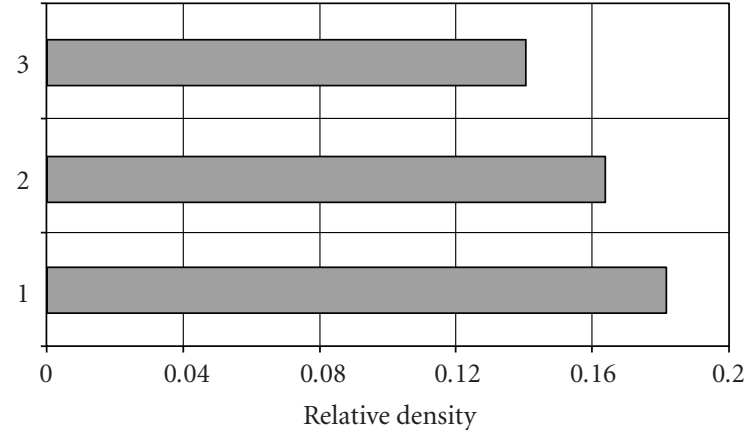

(b)

Figure 7: Relative density gradient for the sample $\mathrm{SM}, \mathrm{N}_{2}$, ambient sectioned in 3 slices.

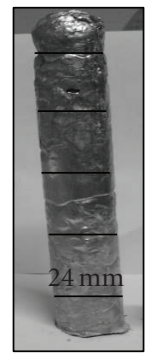

(a)

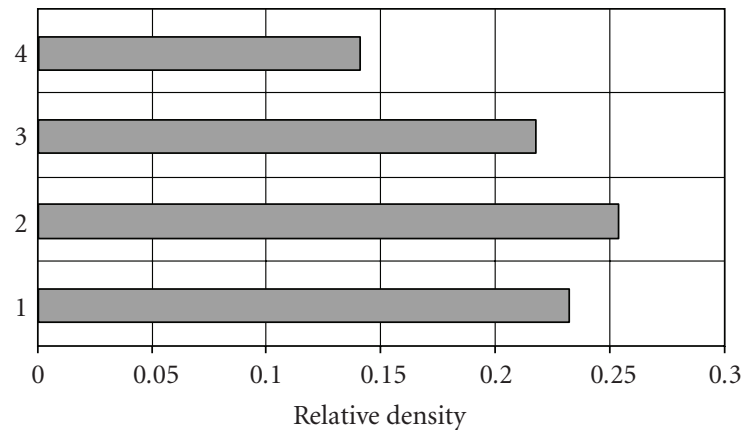

(b)

FIGURE 8: Relative density gradient for the sample BM, air, suction sectioned in four slices.

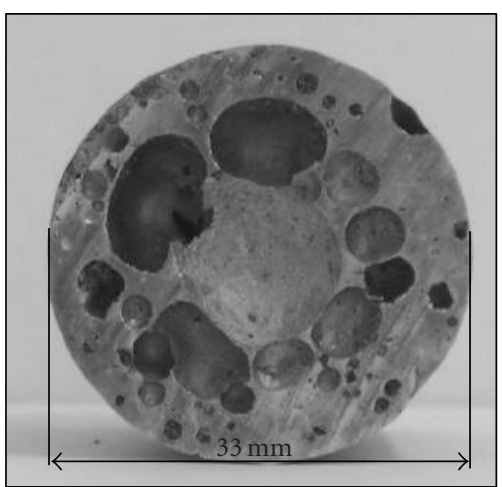

FIGURE 9: Sample BM, (relative density 0.4).

3.3. Relative Density Gradient. During solidification, molten metal drains through the cell membranes due to gravity. As a result of drainage, there is a thick layer of metal at the bottom, and the foam part shows a density gradient through the thickness. To avoid this defect, it is possible to set temperature as low as possible, so keeping viscosity high, or by adding viscosity enhancing substances. This problem was present during experimentation due to the height of the mould. Thus image analysis of the material was performed to document the extent of the density gradient existing in the top, middle, and bottom sectioned specimens.
TABLE 4: Circularity parameter.

\begin{tabular}{lcccc}
\hline Mould type & Pressure & Gas & $C$ range & $C$ average value \\
\hline SM & Ambient & Nitrogen & $0.33-0.95$ & 0.799 \\
SM & Suction & Nitrogen & $0.43-0.94$ & 0.912 \\
ME & Ambient & Air & $0.28-0.92$ & 0.663 \\
ME & Suction & Nitrogen & $0.57-0.96$ & 0.947 \\
BM & Suction & Nitrogen & $0.52-0.93$ & 0.903 \\
BM & Suction & Air & $0.57-0.95$ & 0.862 \\
\hline
\end{tabular}

Figure 6 shows an uneven density distribution within the specimen cross section, and two regions of different cellular structures are marked as example: the upper with elongated pores and the lower with big pores. Each of them can be regarded as a different cell architecture that can define a subdomain. This problem exists strictly for casting in a similar way, where material properties depend on the solidification process (especially from the solidification rate) and vary across the thickness of the part. Thus, for example, the rate of cooling and thus solidification of particular molten metals can affect the microstructure of the finished metal structure. The inhomogeneities of cellular metal have to be quantified in their range of variation and with respect to their location within the samples.

Cylindrical samples, obtained by simple mould, have been sectioned in three slices, each of thickness of about 


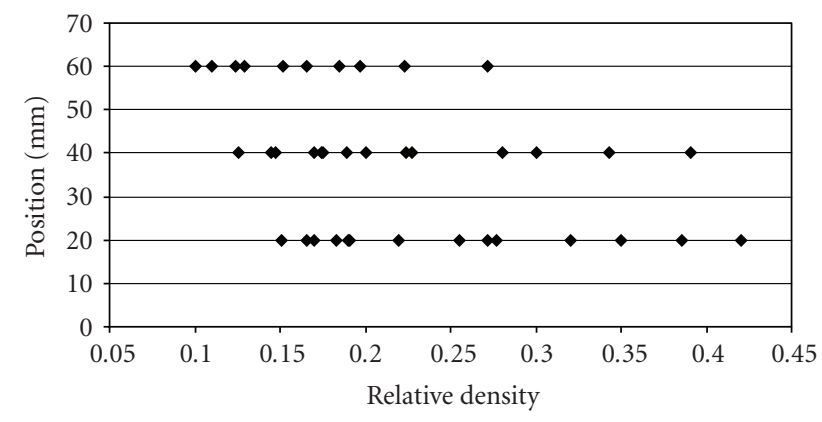

FIGURE 10: Relative density gradient data.

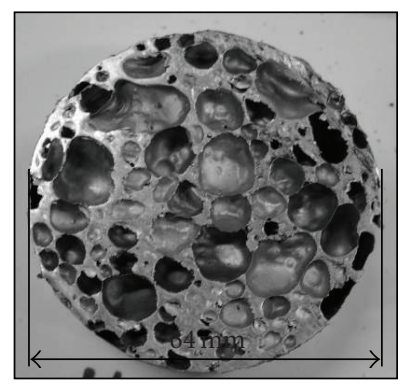

FIGURE 11: Cross section of sample showing skin region (SM, nitrogen, ambient).

$20 \mathrm{~mm}$. A density gradient diagram of one sample is reported in Figure 7. Only one sample shows an anomalous behavior with an inverted density gradient, because the lower slice is completely empty, and thus it is lighter than the upper part. The samples obtained by bars mould have been sectioned in 4 layers, each of thickness of $20 \mathrm{~mm}$ (Figure 8). Only one sample shows an anomaly because the relative density figure (average value of 0.4 ) is higher than the average value of the other samples (usually 0.2 ), and this problem is probably due to a casual error in the test execution. The sample presents a little number of bubbles inside even if the external part seems normal, and it is showed in Figure 9.

Excluding from the following consideration the strange cases previously presented, the course about the density gradient is as expected. Nevertheless, it should be noted that a uniform structure is not always necessary but it depends on the application. For instance, natural load bearing structures, as bones, are not also uniform and isotropic, because they have an optimum distribution of the cell material according to the loading requirements. Therefore, the challenge is not always to get uniform structures but to achieve the reproducible properties with a predetermined nonuniform structure [14]. Figure 10 reports the relative density gradient data showing variation in thickness direction of foam slab. More than $80 \%$ of the samples are in the range of relative density $0.1-0.3$, and only a few of them overcome this range.

Obtained cellular metal parts are usually surrounded by a metal skin. The oxide content is much higher on interior cell surfaces, because that skin was exposed directly to the atmosphere in the liquid state and during solidification and

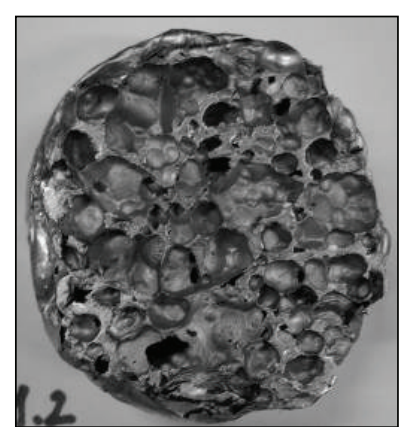

(a)

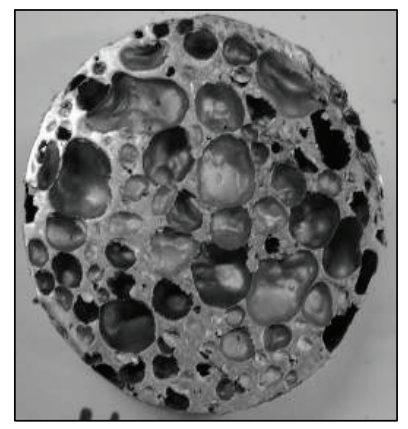

(b)

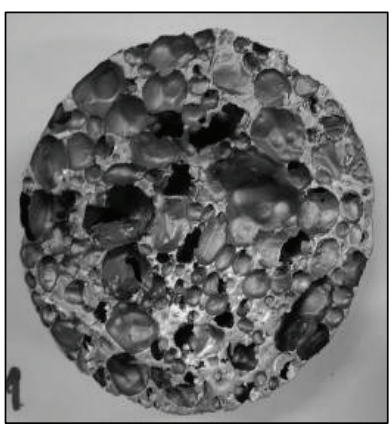

(c)

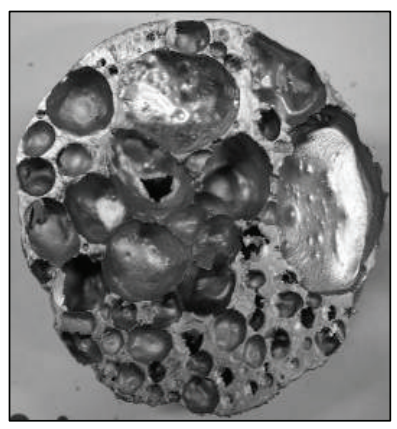

(d)
FIGURE 12: Different pore shape using different pressure and at different thickness position: (a) upper and (b) lower slice at ambient pressure; (c) upper and (d) lower slice with suction (Ø64).

cooling. This skin region can be deduced from Figure 11 where the local density is different from other parts.

3.4. Cells Area and Shape. The significant structural features of foam parts are the shape and size of pores. But even if the cell size is uniform and the pores are arranged regularly, this information is not sufficient to describe the cellular metal. Also pores can take preferred orientations. By visual inspection, all samples were evaluated, and the pores size was measured by software tool.

Relative to the bubbles shape, the presence of irregular structures was observed depending on the dimension of the cells apparently positioned in preferential zones. The cells spherical and of medium dimensions are localized in proximity of the base of specimen. Cells of polyhedral shape and showing bigger areas are in proximity of the top and in some case in the middle section, and that is due to the coalescence effects.

Figures 12(a)-12(b) and 12(c)-12(d) show two samples realized with simple mould and using nitrogen as foaming gas. The samples to the left are realized at ambient pressure: (a) the upper and (b) the lower slice. The sample to the right are realized with suction, and (c) and (d) are the upper and lower slice. The foam specimens, realized at ambient pressure, present more regular pores distribution and slightly small bubbles.

The pure air, as foaming gas, led to more frequent corrugated bubbles, contrary to nitrogen foamed material (Figure 13), differently from other investigation results [15]. 


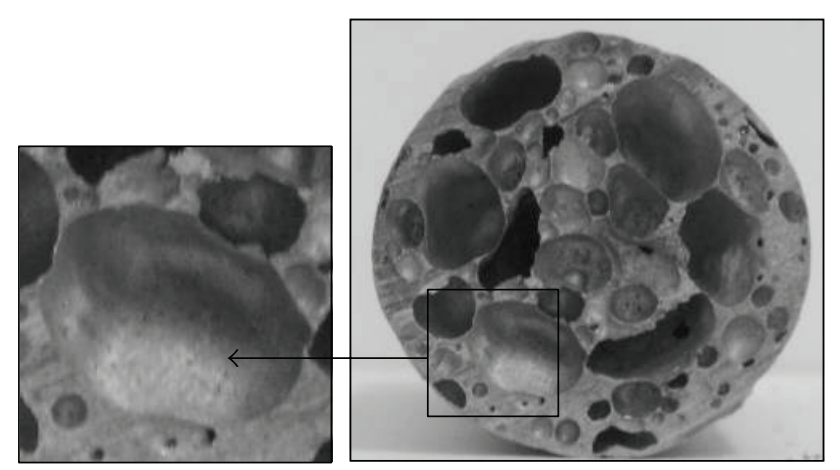

(a)

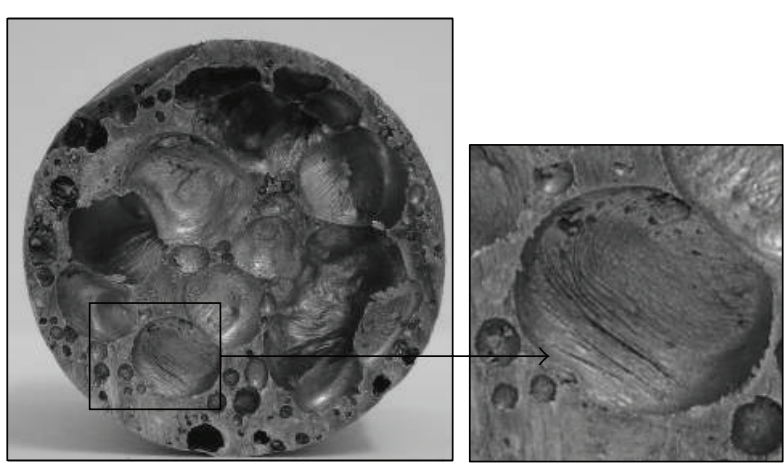

(b)

FIGURE 13: Corrugated cell walls due to different foaming gas (BM, suction): (a) nitrogen and (b) air.

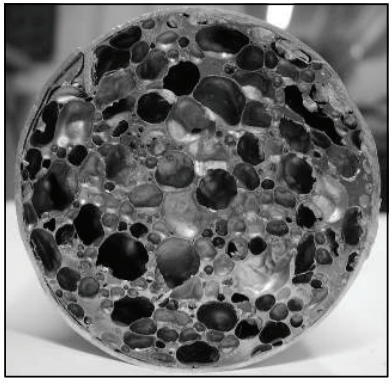

(a)

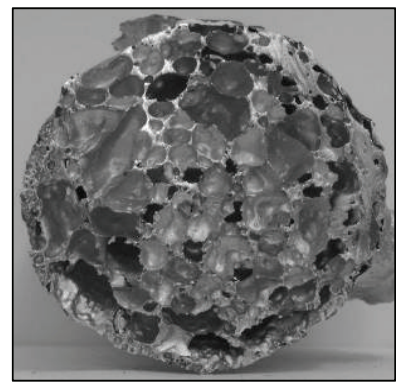

(b)
FIGURE 14: Different foaming gas (SM, ambient, Ø64): (a) nitrogen and (b) air.

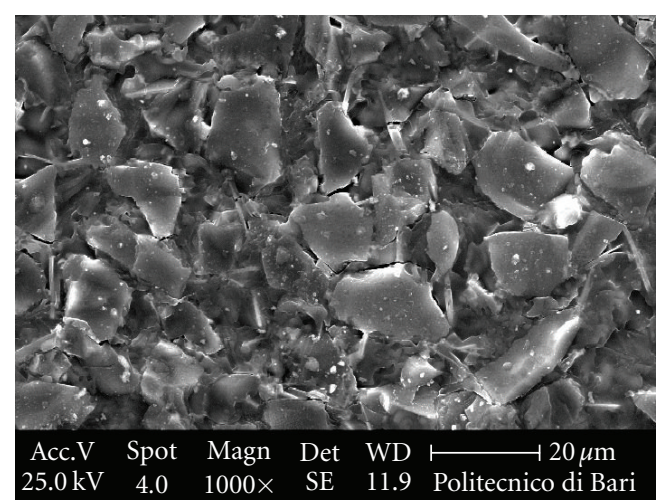

FIGURE 15: SEM image of SiC particles at the surface of $\mathrm{N}_{2}$ foamed wall bubble (SM, nitrogen, ambient).

Corrugated cell walls are typically found in metal foams which have rather thin cell walls compared to the cell size. Curved or corrugated cell walls occur during forming or on solidification. The face corrugations observed in the cell walls are possibly caused either by shrinkage of the wall solid during solidification or by the partial collapse of the cell walls under an applied force (i.e., manipulation during production or the weight of the foam itself). In each case, both the axial stiffness and the flexural rigidity of the curved or corrugated

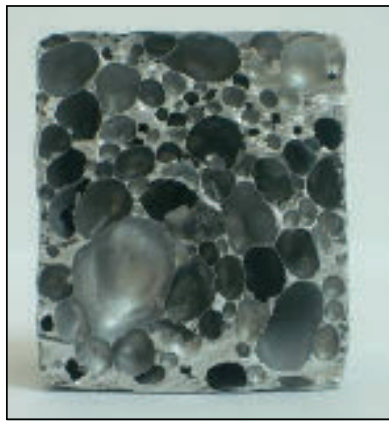

(a)

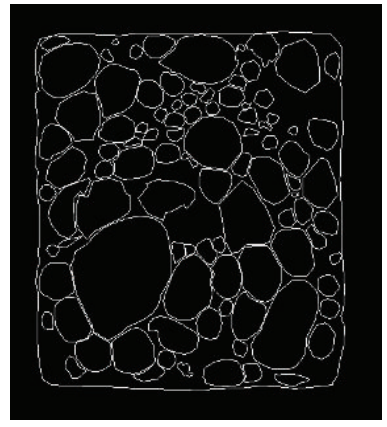

(b)
Figure 16: Geometrical structure of foam $(l=32 \mathrm{~mm})$.

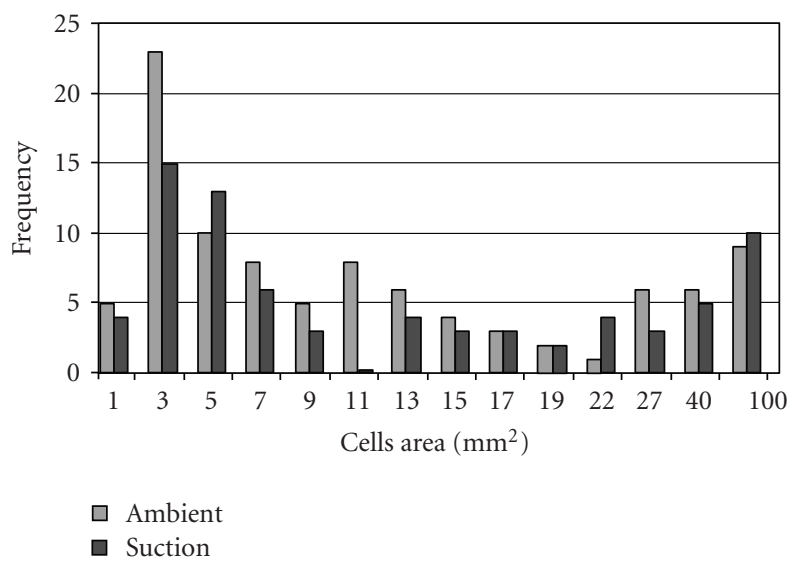

FIgURE 17: Pore size distribution (SM, nitrogen).

structural member are reduced [16]. Literature reports that the curvature and corrugations may account for up to a $70 \%$ drop in the modulus, and strength of foams below the values is estimated for planar cell walls [17]. The face wrinkling can be avoided by reducing the stress applied to the foam immediately after solidification and by reducing the rate of cooling [18].

It was also observed that the samples produced by air show more elongated bubbles than the sample foamed by 


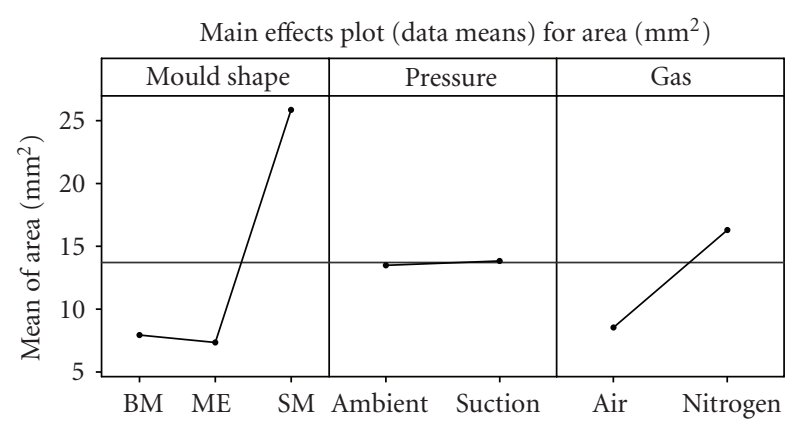

(a)

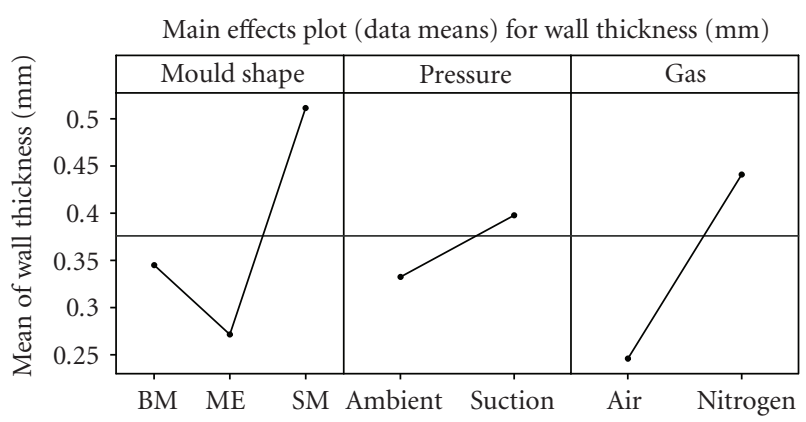

(b)

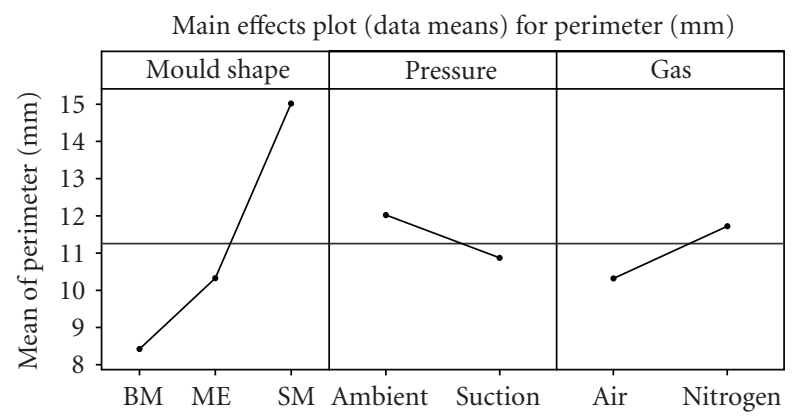

(c)

FIGURE 18: Area, perimeter, and wall thickness of cells versus process parameters.

blowing nitrogen that are circular (Figure 14). Moreover nitrogen leads to bubbles with dark inner wall compared with that of bubbles obtained by air. An investigation by SEM of inner surface of the foam bubbles manufactured with nitrogen revealed that the $\mathrm{SiC}$ particles are relatively dense on the surface (Figure 15). The SiC particle concentration in the cell walls of the foam bubbles is higher in samples foamed by nitrogen than in those by air. Moreover, no surface layer covering the $\mathrm{SiC}$ particles is formed by nitrogen. Previous analysis of the concentration depth profiles of cell walls verifies the increase of the thickness of the oxide layer with increasing oxygen concentration in the blowing gas. The oxide layer increases bubble stability more than the higher particle concentration in the cell walls of foam samples produced with nitrogen [19].
Measurements of the pores size for samples were realised by a software image tool, implemented by authors in a commercial software, that can define the pore boundaries by means of pixel contrast. Each sample picture was imported in the software, and the cell geometry was reconstructed (Figure 16). The results obtained from measurements are reported in Figures 17 and 18. In Figure 17, each value of the abscissa represents the upper limit of measured area range (inferior limit of the range is the previous abscissa value), and the ordinate represents the number of cells included in this range.

Observing all the results, it is possible to consider that

(i) the cells, whose area is lower than the average total value of $10 \mathrm{~mm}^{2}$, are $75 \%$ of the total cells number, while $23 \%$ oscillate up to the limit of $24 \mathrm{~mm}^{2}$; the remaining $2 \%$ of cells present area wider than $30 \mathrm{~mm}^{2}$;

(ii) $50 \%$ of cell areas result in the range of $3.1-28.3 \mathrm{~mm}^{2}$ comparable to literature values [20];

(iii) the variability of the perimeters is wide, and this demonstrates a certain irregularity of cells shape. Approximately $54 \%$ of the measured perimeters are lower than the average value of $11.75 \mathrm{~mm}$;

(iv) relatively to the cell walls, it is observed that the frequent thicknesses are in the range $0.1-0.6 \mathrm{~mm}$. $90 \%$ of cell wall thickness results in the range of 0.48 $1.44 \mathrm{~mm}$ as presented in literature [20].

The cells sphericity evaluation has been carried out by calculating the circularity parameter [21]. Estimating the results emerges that values over 0.9 are caught up using nitrogen with suction. The obtained figures are high, and this result implies that there are many cells with regular shapes and contours (Table 4).

\section{Conclusions}

The present study investigated aluminum foams manufactured by the new MGI-mould process. Several conclusions can be drawn as follows.

(1) The new MGI-mould process was capable of producing the near net shape aluminum foam parts with length of about $200 \mathrm{~mm}$ and different shapes with skin surface and good internal quality especially for the core of automotive articles.

(2) The disadvantage of the traditional MGI process (the brittleness due to the reinforcing particles contained in the cell walls) could be overcome, as presented in this investigation, with the production of near net shape foam.

(3) Large volume of foam can be produced, and low densities can be achieved. Density gradient is often evident. The circularity parameter can reach the value of 0.95 .

(4) The results and distribution of properties depend mainly on the mould shape and foaming gas. 


\section{Acknowledgment}

Financial support from research Project PRIN 06 - TILAS (Innovative Manufacturing Technologies for Metal Foams) is acknowledged.

\section{References}

[1] J. T. Wood, "Production and applications of continuously cast, foamed aluminum," in Proceedings of Fraunhofer USA Metal Foam Symposium, J. Bahart and H. Eifert, Eds., pp. 31-36, MIT, Stanton, Del, USA, October 1997.

[2] P. Åsholt, "Aluminium foam produced by the melt foaming route-process, properties and applications," in Proceedings of the 1st International Conference on Metal Foam and Porous Metal Structures (MetFoam '99), J. Banhart, M. F. Ashby, and N. A. Fleck, Eds., pp. 133-140, MIT, Bremen, Germany, June 1999.

[3] S. W. Ip, Y. Wang, and J. M. Toguri, "Aluminum foam stabilization by solid particles," Canadian Metallurgical Quarterly, vol. 38, no. 1, pp. 81-92, 1999.

[4] G. Kaptay, "Interfacial criteria for stabilization of liquid foams by solid particles," Colloids and Surfaces A, vol. 230, no. 1-3, pp. 67-80, 2003.

[5] B.-Y. Hur, S.-H. Park, and A. Hiroshi, "Viscosity and surface tension of $\mathrm{Al}$ and effects of additional element," Materials Science Forum, vol. 439, pp. 51-56, 2003.

[6] J. T. Beals and M. S. Thompson, "Density gradient effects on aluminium foam compression behaviour," Journal of Materials Science, vol. 32, no. 13, pp. 3595-3600, 1997.

[7] H. Sang, L. D. Kenny, and I. Jin, "Process for producing shaped slabs of particle stabilized foamed metal," US patent no. 5334236, 1994.

[8] L. D. Kenny and M. Thomas, "Process for shape casting of particle stabilized metal foam," US patent no. 5281251, 1994.

[9] S. Kleinheyer and G. Bilz, "Process and apparatus for manufacturing formed (shaped, moulded) parts from metal foam," German patent no. DE4326982, 1995.

[10] S. Nichol, "Metal foam casting apparatus and method," US patent no. 6998535, 2006.

[11] A. J. Clegg, Precision Casting Processes, Pergamon Press, Oxford, UK, 1991.

[12] C. Korner, F. Heinrich, and R. F. Singer, "Foam cores for encasing by casting," in Handbook of Cellular Metals: Production, Processing, Applications, H. P. Degischer and B. Kriszt, Eds., pp. 103-106, Wiley-VCH, Weinheim, Germany, 2002.

[13] R. Surace, L. A. C. De Filippis, E. Niini, A. D. Ludovico, and J. Orkas, "Foaming and compression behaviour of aluminium foam manufactured by Melt Gas Injection," in Proceedings of the 8th AITEM Conference, p. 65, Montecatini Terme, Italy, September 2007.

[14] F. Simančík, "Reproducibility of aluminium foam properties," in Proceedings of the 1st International Conference on Metal Foam and Porous Metal Structures (MetFoam '99), J. Banhart, M. F. Ashby, and N. A. Fleck, Eds., pp. 235-240, MIT, Bremen, Germany, June 1999.

[15] N. Babcsán, D. Leitlmeier, and H. P. Degischer, "Foamability of particle reinforced aluminum melt," Materialwissenschaft und Werkstofftechnik, vol. 34, no. 1, pp. 22-29, 2003.

[16] A. E. Simone and L. J. Gibson, "The effects of cell face curvature and corrugations on the stiffness and strength of metallic foams," Acta Materialia, vol. 46, no. 11, pp. 39293935, 1998.
[17] J. L. Grenestedt, "Influence of wavy imperfections in cell walls on elastic stiffness of cellular solids," Journal of the Mechanics and Physics of Solids, vol. 46, no. 1, pp. 29-50, 1998.

[18] A. E. Simone and L. J. Gibson, "Aluminum foams produced by liquid-state processes," Acta Materialia, vol. 46, no. 9, pp. 3109-3123, 1998.

[19] D. Leitlmeier, H. P. Degischer, and H. J. Flankl, “Development of a foaming process for particulate reinforced aluminum melts," Advanced Engineering Materials, vol. 4, no. 10, pp. 735740, 2002.

[20] W. Deqing and S. Ziyuan, "Effect of ceramic particles on cell size and wall thickness of aluminum foam," Materials Science and Engineering A, vol. 361, no. 1-2, pp. 45-49, 2003.

[21] G. Costanza, R. Montanari, and M. E. Tata, "Ottimizzazione del contenuto di $\mathrm{TiH}_{2}$ e $\mathrm{SiC}$ nelle schiume di $\mathrm{Al}$," $\mathrm{La}$ Metallurgia Italiana, vol. 6, pp. 41-47, 2005. 

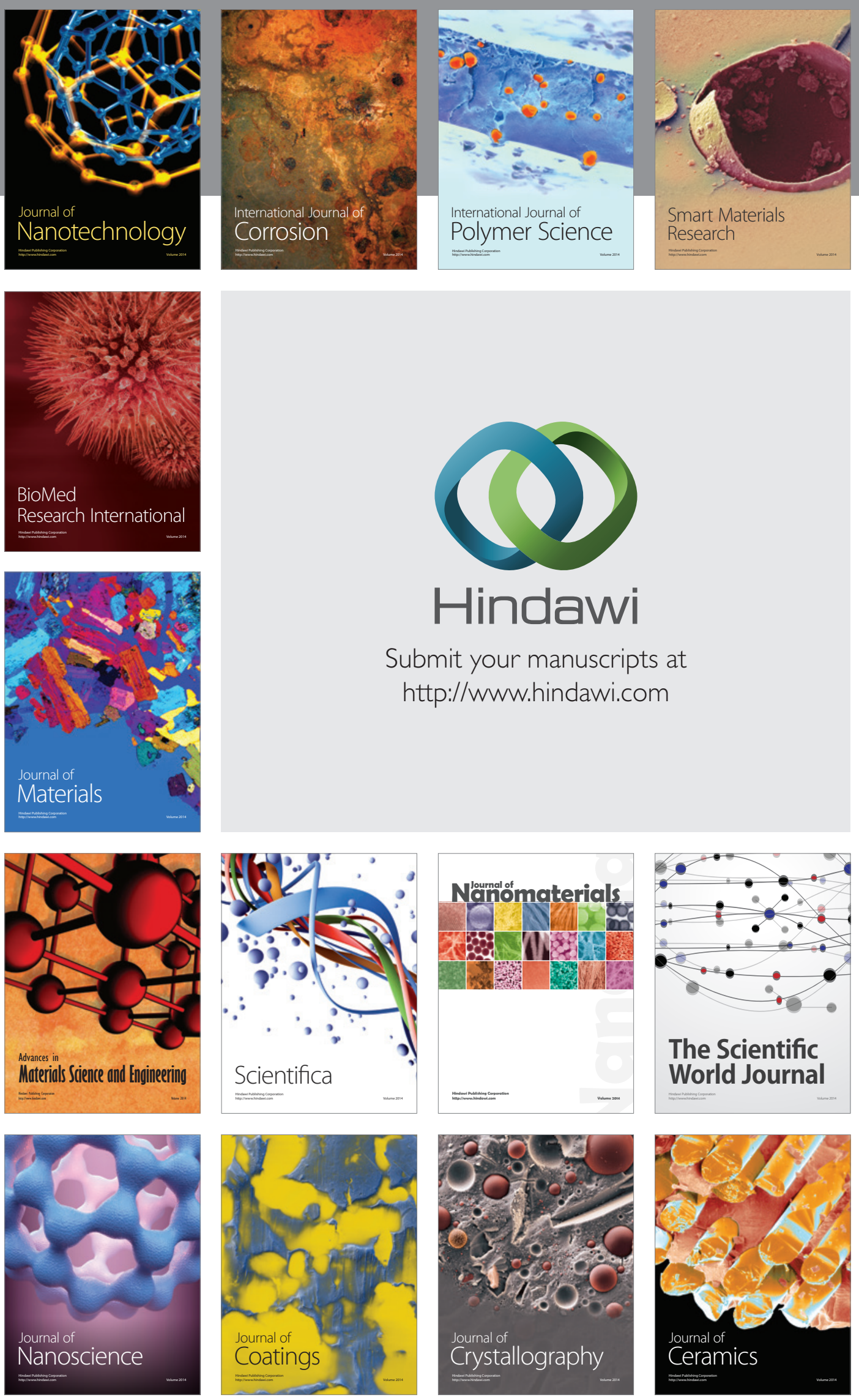

The Scientific World Journal

Submit your manuscripts at

http://www.hindawi.com

\section{World Journal}

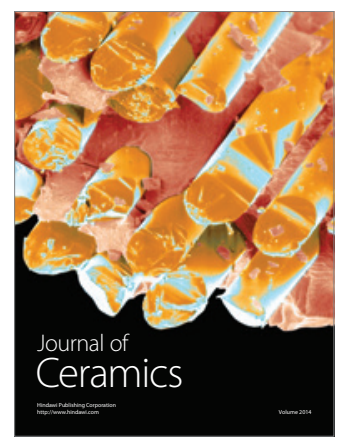

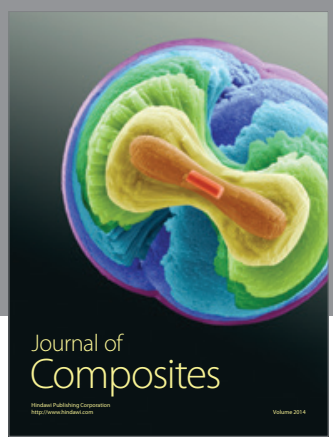
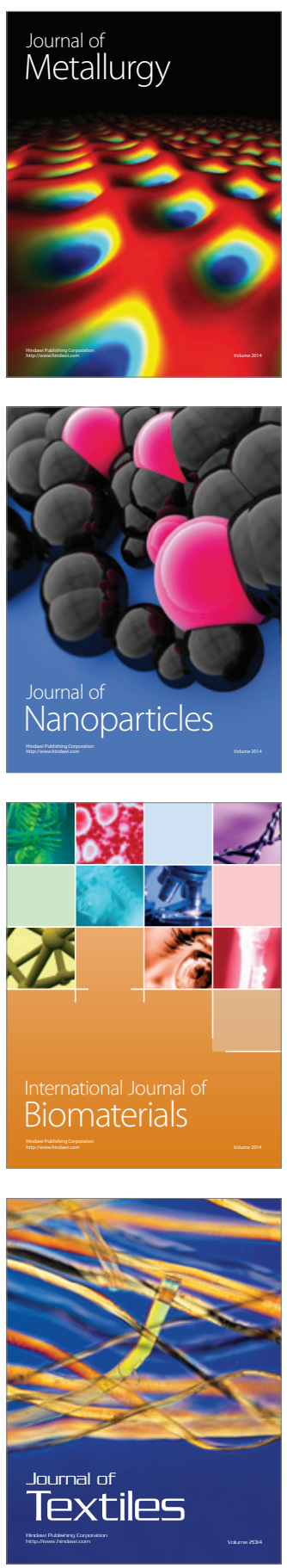